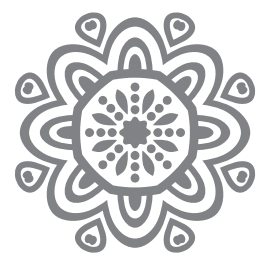

\title{
Membumikan Dakwah Berbasis Komunikasi Profetik Di Era Media Baru
}

\author{
Qurrota $A^{\prime}$ yuni ${ }^{1}$ \\ Konsentrasi Dakwah dan Komunikasi, Jurusan Pengkajian Islam, \\ Sekolah Pascasarjana UIN Syarif Hidayatullah Jakarta \\ Email; qurrotaayuni24@gmail.com
}

\begin{abstract}
As a means of disseminating information, a new era of media does not always have a positive impact on the purpose of da'wah. The new era's media actually raises the birth of da'wah that is extreme, radical and far from the meaning of Islam as a religion of peace. Very few da'wah actors and activists have integrated prophetic ethics and values in the new media era. They use many utterances of hatred (hatespeech) and lies (hoaxes) to preach. This phenomenon is very inversely proportional to the teachings of friendly and peaceful Islam as did the Prophet Muhammad. Therefore, grounding prophetic-based tabligh activities is very urgent in the new media era.
\end{abstract}

Keywords: preaching, the era of new media, prophetic.

\footnotetext{
${ }^{1}$ Mahasiswi Program Magister Konsentrasi Dakwah dan Komunikasi, Jurusan Pengkajian Islam, Sekolah Pascasarjana UIN Syarif Hidayatullah Jakarta. Email; qurrotaayuni24@gmail.com / 085648874474
} 


\section{A. Latar Belakang}

Islam merupakan agama kedamaian dan kasih sayang untuk seluruh manusia dan alam semesta. Agama Islam disampaikan oleh Nabi Muhammad saw melalui cara damai dan persuasif. Banyak dari pihak lawan yang memeluk Islam karena ucapanya yang lembut dan kepribadianya yang baik. Dalam berinteraksi dan bergaul kepada non muslim nabi selalu ramah, berkata jujur dan benar. Kepribadian nabi inilah yang kemudian menjadi salah satu faktor diterimanya agama Islam dengan mudah oleh masyarakat.

Setelah wafatnya nabi, umat Islam berkewajiban untuk melanjutkan misi nabi dalam berdakwah. Setiap dari mereka mengemban tugas dan tanggung jawab dalam menyebarkan Islam yang rahmatan lil'alamin. Bagi setiap umat Islam, dakwah adalah sebuah tanggung jawab moral yang bersifat individual yang diwariskan sebagai tugas kenabian.(Fakhrurroji; 2017). Kewajiban dakwah ini diungkapkan Allah dalam QS. Ali 'Imran ayat 104;

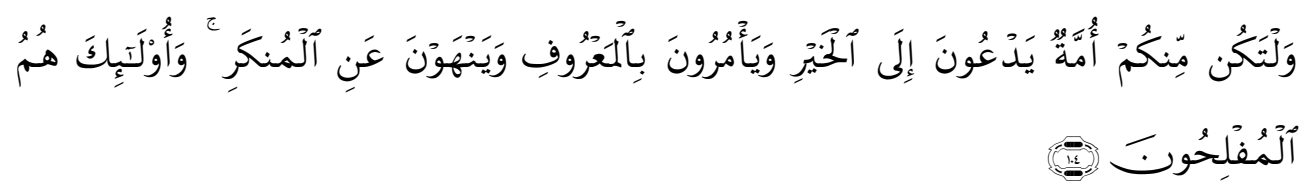

Artinya; "Dan hendaklah ada di antara kamu segolongan umat yang menyeru kepada kebajikan, menyuruh kepada yang ma'ruf dan mencegah dari yang munkar, merekalah orang-orang yang beruntung."

Perkembangan teknologi komunikasi yang semakin canggih memudahkan tersebarnya dakwah secara masif. Jika dahulu kala dakwah hanya terbatas di masjid atau musholla, dakwah masa kini tidaklah demikian. Setiap orang dapat berdakwah di manapun dan kapanpun melalui platform-platform seperti youtube, facebook, dan whatsup. Bentuk dakwahnya pun sangat bervariatif, mulai dari ceramah dalam bentuk video ataupun tulisan berupa artikel, status, dan qoutes.

Sayangnya, kebanyakan penyebaran dakwah yang massif ini tidak didukung dengan prinsip-prinsip dakwah yang baik. Banyak sekali konten dakwah yang lebih mengedepankan prinsip kekerasan (kasar) dalam ucapan, ujaran kebencian (hatespeech) dan kebohongan (hoax) daripada perdamaian dan kebenaran. Sebagaimana laporan Kementrian informasi pada Desember 2017 terdapat 800 ribu situs telah menyebarkan Hoax. Pada tahun yang sama pula, peningkatan kasus yang ditangani polri terkait kejahatan ujaran kebencian naik dengan pesat sebesar 44,99\% dari 1.829 menjadi 3.325 kasus.

Dalam laporan survey oleh Daily Social pada 2018, tingkat penyebaran hoax tertinggi berada di platfrom Facebook dengan jumlah 82,25 \%. Peringkat 
kedua banyaknya informasi hoax berada di media sosial WhatsApp dengan jumlah 56,55\%, dan terakhir instagram dengan jumlah 29,48\%. Fenomena hoax dalam dakwah dikuatkan dengan adanya pemblokiran kembali 11 situs Islam oleh Kemeninfo pada tahun 2017 setelah pemblokiran 22 situs Islam pada tahun 2015.

Pemblokiran situs Islam atau media dakwah berlabel Islam ini disebabkan konten dakwah yang mengandung berita bohong (hoax) dan isu suku, agama, ras dan antargolongan (SARA) yang meresahkan masyarakat. Banyaknya dakwah berbasis informasi hoax yang membanjiri cyberspace ini sangat tidak sesuai dengan prinsip dakwah Islam. Di mana kebenaran dan kejujuran menjadi faktor utama dalam penyampaian pesan-pesan dakwah.

\section{B. Definisi Dakwah}

Secara bahasa, dakwah berasal dari Bahasa Arab yang berarti panggilan, ajakan, atau seruan. Kata ini merupakan bentuk mashdar dari fi'il (kata kerja) دعا-يدعوا-دعوة yang berarti mengajak, memanggil, atau menyeru. Kata dakwah dalam al-Qur'an disebutkan kira-kira sebanyak 198 kali yang tersebar dalam 55 surat (176 ayat) (Abdul Basit; 2005). Di antaranya adalah QS. An-Nahl; 44, 125, AlMaidah; 67, Al-Ahzab; 45, dan Al-Jum'ah; 2.

Dakwah secara istilah sebagaimana yang diungkapkan oleh Syekh Ali Mahfuz dalam Hidayah al-Mursyidin adalah mengajak manusia ke jalan kebaikan dan petunjuk untuk memperoleh kebahagiaan di dunia dan akhirat (Mahfuz, 1976; 15). Sedangkan dakwah menurut Syukriadi Sambas $(1995 ; 38)$ adalah proses transmisi, transformasi, dan internalisasi ajaran Islam dengan menggunakan metode, media, dan untuk mencapai tujuan tertentu.

Definisi di atas menunjukkan bahwa lingkup aktivitas dakwah sangatlah luas. Dakwah tidak hanya diidentikkan dengan ceramah atau pidato sebagaimana yang dipahami secara umum. Dakwah merupakan proses mengajak manusia kepada Islam yang dilakukan dengan lisan (da'wah bil al-lisan), ataupun tulisan (da'wah bi al-qalam), dan juga perbuatan (da'wah bil al-hal) atau aksi sosial Islam (da'wah bi ahsan al-mal) (Enjang dan Aliyudin, 2009; 12). Hal ini sebagaimana yang tertera dalam al-Qur'an surat Fushilat (41) ayat 33;

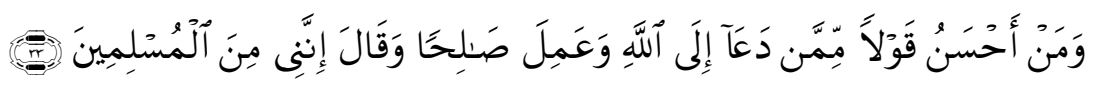

Artinya; "siapakah yang lebih baik perkataannya daripada orang yang menyeru kepada Allah, mengerjakan amal yang saleh, dan berkata: "Sesungguhnya aku Termasuk orang-orang yang menyerah diri?" 
Secara umum, aktivitas dakwah memiliki dua dimensi besar, yakni dimensi kerisalahan dan kerahmatan yang satu sama lain tidak bisa dipisahkan (Fakhrurroji, 5; 2017). Dimensi kerisalahan dalam dakwah merupakan upaya mentransformasikan ajaran agama oleh para rasul kepada umat manusia. Adapun dimensi kerahmatan merupakan pengejawantahan konsep Islam rahmatan lil 'alamin dalam seluruh kehidupan manusia tanpa terkecuali. Kedua dimensi dalam dakwah tersebut bertujuan untuk menciptakan perubahan kondisi masyarakat yang lebih baik sesuai dengan ajaran dan nilai-nilai Islam. Prinsip ini sesuai dengan firman Allah dalamAl-Qur'an surat Ali-'Imran ayat 104, yang berbunyi;

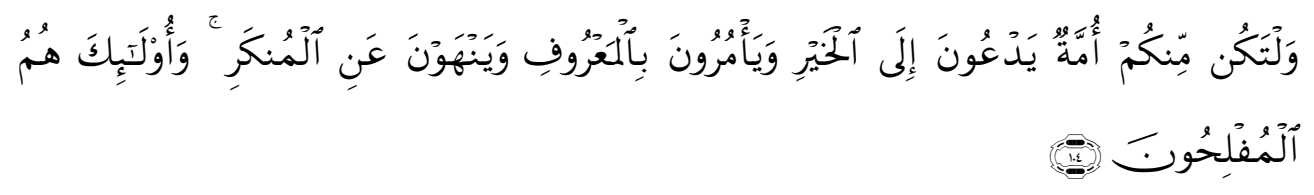

Artinya; "dan hendaklah ada di antara kamu segolongan umat yang menyeru kepada kebajikan, menyuruh kepada yang ma'ruf dan mencegah dari yang munkar, merekalah orang-orang yang beruntung."

\section{Perdebatan Dakwah dan Komunikasi}

Secara etimologi, komunikasi berasal dari bahasa Inggris to communiate atau dalam bentuk kata bendanya, communication yang berarti menyampaikan. Adapaun secara terminologi menurut Harold Lasswell adalah who says what in which channel to whom with what effect (Siapa berkata apa melalui saluran kepada siapa berpengaruh apa). Dalam pengertian lain menurut Everett M. Rogers, komunikasi adalah proses di mana ide dialihkan dari sumber satu kepada satu penerima atau lebih dengan maksud untuk mengubah tingkah laku mereka.

Berdasarkan definisi di atas, aktivitas dakwah dan komunikasi secara sepintas tampak sama. Keduanya berorientasi pada penyampaian pesan kepada orang lain yang disertai dengan adanya feedback atau pengaruh. Persamaan ini oleh sebagian ahli dijadikan sebagai acuan bahwa dakwah merupakan bagian dari aktivitas komunikasi. Akan tetapi Muhtadi (2012;7) mengungkapkan bahwa keduanya memiliki perbedaan konseptual yang demikian tegas, yang masingmasing memiliki objek kajian yang berbeda. Jika objek dakwah adalah manusia dan perubahan perilakunya, objek komunikasi adalah informasi atau komunikasi itu sendiri (Mufid, 2012; 95).

Dakwah bahkan memiliki lingkup kajian luas dan tidak hanya terbatas pada "menyampaikan" atau menginformasikan sebagaimana komunikasi. Aktivitas dakwah memiliki empat dimensi dan cakupan yang meliputi tabligh 
(menyampaikan), irsyad (bimbingan), tadbir (pemberdayaan manusia), dan tahwir atau tamkin (pemberdayaan ekonomi).

Tabligh berorientasi pada proses penyebarluasan agama Islam melalui pemancaran atau sarana transmisi (Kusnawan, 2009; 18) seperti televisi, radio, surat kabar ataupun internet. Sedangkan irsyad mengacu pada upaya bimbingan dan penyuluhan dalam bentuk konseling atau psikoterapi Islam. Tadbir adalah upaya pemberdayaan umat Islam melalui lembaga atau organisasi kemanusiaan. Adapun tahtwir atau tamkin merupakan upaya pemberdayaan ekonomi keumatan pada masyarakat Islam.

Lingkup dakwah yang sangat luas tersebut secara tidak langsung menunjukkan bahwa dakwah bukanlah bagian dari komunikasi. Ia memiliki orientasi dan tujuan yang lebih luas dan bervariasi dari komunikasi. Oleh sebab itu, gagasan yang paling dekat dengan aktivitas komunikasi adalah dakwah dalam konsep tabligh (menyampaikan). Konsep ini tidak hanya terbatas pada aktivitas ceramah ataupun pidato, akan tetapi tulisan atau karya jurnalistik. Dakwah dalam bentuk jurnalistik (korespondensi) juga pernah dilakukan oleh Nabi Muhammad dalam berdakwah, seperti surat berisi ajakan untuk memeluk Islam yang disampaikan kepada Raja Najasyi, Kaisar Heraclius, Kisra Persia, Al-Mauquqis, Al-Harits Al-Ghassani, dan Haudah Al-Hanafi (Mustafa Ya'qub, 2014; 181-201).

\section{Aktivisme Dakwah di Cyberspace (Era Media Baru)}

Cyberspace merupakan gabungan dari kata dalam bahasa Inggris cyber dan space. Dalam Dictionary of Media Studies, cyberspace diartikan sebagai national spacewhere internet activity take places, by analogy to real, physical space (ruang nasional tempat aktivitas internet berlangsung, dengan analogi dengan ruang fisik yang nyata) (Barker, 2006; 59). Istilah cyberspace pertama kali dimunculkan oleh William Gibson pada 1984 dalam novelnya Neuromancer yang didapatkan dari fenomena keyakinan anak-anak setelah bermain video games (Ruli Nasrullah, ;2016 18). Cyberspace menjadi istilah yang sering digunakan untuk menunjuk pada ranah metaforis komunikasi elektronik. (Iswandi, 33), serta ruang virtual yang tercipta melalui koneksi internet (Fakhrurroji, 2017; 77).

Setelain internet, Cyberspace juga sebuah istilah yang digunakan untuk merujuk pada media era baru. Era media baru adalah era di mana media memiliki konsep interactivy (interaksi) antara khalayak dengan sumber berita. Perubahan pada era ini ditandai dengan adanya perkembangan teknologi, cakupan area, produksi massal, distribusi massal, dan efek yang berbeda dari media massa (Ruli Nashrullah, 2016; 13). Fenomena ini menunjukkan bahwa komunikasi yang 
terjadi tidak lagi bersifat one way seperti pada era broadcasting (era pertama), akan tetapi interkoneksi atau ketersaling hubungan satu samalain. Lebih jauh lagi, internet kini telah membentuk ruang maya sebagai tempat bertegur sapa secara interaktif (Muhtadi, 2012; 60).

Tabel. 1

Perbedaan antara Era Media Pertama dan Kedua

\begin{tabular}{|l|l|}
\hline Era Media Pertama (Broadcast) & Era Media Kedua (Interactivy) \\
\hline $\begin{array}{l}\text { Tersentral (dari satu sumber ke banyak } \\
\text { khalayak }\end{array}$ & $\begin{array}{l}\text { Tersebar (dari banyak sumber ke banyak } \\
\text { khalayak) }\end{array}$ \\
\hline Komunikasi terjadi satu arah & $\begin{array}{l}\text { Komunikasi terjadi timbal balik atau dua } \\
\text { arah }\end{array}$ \\
\hline $\begin{array}{l}\text { Terbuka peluang media atau sumber untuk } \\
\text { dikuasai }\end{array}$ & $\begin{array}{l}\text { Tertutupnya penguasa media dan bebasnya } \\
\text { kontrol terhadap sumber }\end{array}$ \\
\hline $\begin{array}{l}\text { Media merupakan instrumen yang melang- } \\
\text { gengkan strata dan kelangengan sosial }\end{array}$ & $\begin{array}{l}\text { Media memfasilitasi setiap khalayak (warga } \\
\text { negara) }\end{array}$ \\
\hline $\begin{array}{l}\text { Terfregmentasinya khalayak dan dianggap } \\
\text { sebagai massa }\end{array}$ & $\begin{array}{l}\text { Khalayak bisa terlihat sesuai dengan karakter } \\
\text { dan tanpa meninggalkan keragaman } \\
\text { identitasnya masing-masing. }\end{array}$ \\
\hline $\begin{array}{l}\text { Media dianggap dapat atau sebagai alat } \\
\text { memengaruhi kesadaran }\end{array}$ & $\begin{array}{l}\text { Media melibatkan pengalaman khalayak baik } \\
\text { secara ruang maupun waktu. }\end{array}$ \\
\hline
\end{tabular}

Sumber; Buku Teori dan Riset Media Siber (Cybermedia), (Ruli Nasrullah, 2016; 14)

Internet dalam bahasa Marshall McLuhan disebut dengan global vilage (desa buana). Istilah ini merujuk pada globalisasi arus informasi pada internet yang menyajikan segala kebutuhan manusia dalam satu wadah. Oleh karenanya tidaklah heran jika internet menjadi ruang virtual yang digemari oleh masyarakat. Dalam laporan survey yang dilakukan oleh Asosiasi Penyelenggara Jasa Internet Indonesia (APIJI), 143 juta penduduk Indonesia telah menggunakan jaringan internet sepanjang tahun 2017. Jumlah ini menjadikan Indonesia berada di peringkat ke 6 dunia dalam penggunaan internet setelah Jepang.

Sebagai jejaring network yang menghubungkan banyak koneksi dengan seluruh manusia di dunia ini, internet banyak digunakan untuk media dakwah. Fenomena ini dapat dilihat dari banyaknya akun-akun Islam yang muncul di berbagai platform facebook, youtube, Whatsup, instagram, ataupun Line. Seperti akun Foto Dakwah, Muslim.or.id, Konsultasi Syariah, Pengusaha Muslim, Trandsetteer Kebaikan yang ada di Facebook. Akun dakwah di instagram seperti @indonesiabertauhidofficial, @teladan.rasul, @tausiyahku, @duniajilbab, @ beraniberhijrah, dll. Sedangkan media Islam melalui platform Grup Whatsup seperti Rumah Dakwah Indonesia (RDI), Kajian iMan dan Islam (MANIS), 
Majelis Qur'ani, One Day One Jus (ODOJ). Situs dan blog seperti Rumahsyo. com, Manhaj.com, Islami.co, Bincang Syariah.com, Eramuslim.com, dll.

Data di atas menunjukkan bahwa betapa internet bukan lagi dianggap sebagai media pembawa pesan semata. Ia telah berubah menjadi media yang menciptakan hubungan dan interasksi simbolik antara informan dengan penerima pesan. Bahkan dalam konteks masyarakat jejaring, sulit sekali membedakan siapa informan dan siapa penerima. Hal ini dikarenakan aturan yang berlaku di cyberspace tidak mengikat dan terkontrol layaknya di dunia nyata. Oleh karenanya, internet telah berubah menjadi rumah, perpustakaan, toko, bioskop, televisi, tempat rekreasi, ruang komunitas, bahkan sebagai wadah ekspresi keagamaan (Muhtadi, 2012; 59).

Aktivisme dakwah di internet tersebut dapat diidentifikasi sebagai fenomena yang berbeda-beda. Pertama, sebagai upaya domestikasi teknologi oleh agama, yaitu menjadikan teknologi sebagai teman akrab bagi penyebaran nilai-nilai agama. Fenomena ini terjadi untuk mensejajarkan teknologi sebagai wajah modernitas dengan agama sebagai kesatuan. Kedua, sebagai upaya konstruksi identitas agama. Artinya bahwa dakwah menjadu usaha strategis dalam membangun identitas melalui simbol-simbol keagamaan dan memperjelas perbedaan dengan identitas individu atau kelompok-kelompok lainya (Fakhruroji, 2017; 191).

Ketiga, bentuk aksi solidaritas keumatan. Fenomena dakwah Islam seperti ini dalam pandangan Wiktorowicz sebagai upaya pembelaan terhadap kepentingan umat Islam (Fakhruroji, 2017; 192). Keempat, sebagai bentuk perlawanan. Aktivitas dakwah Islam dalam fenomena ini hadir sebagai bentuk tandingan bagi lahirnya sekularisme di jejaring sosial. Sekaligus sebagai respon umat Islam terhadap fenomena-fenomena mainstream yang bertentangan dengan nilai-nilai Islam di internet.

Kelima, tindakan antisipasi atas keberlimpahan informasi. Kehadiran internet dilihat sebagai upaya untuk melindungi umat Islam dari informasiinformasi yang merugikan. Dengan menciptakan akun Islami, memperkaya konten Islami dan membentuk lingkungan Islami di cyberspace, umat Islam akan terfilter dari konten-konten yang merusak hakikat Islam itu sendiri.

\section{E. Konsep Komunikasi Profetik}

Aktivitas komunikasi (tabligh) secara historis telah berlangsung sejak interaksi manusia di muka bumi terjadi. Komunikasi dalam arti yang sempit bertujuan untuk menyampaikan pesan atau informasi kepada seseorang atau sekelompok orang. Dalam makna yang luas, komunikasi diproyeksikan sebagai 
proses memengaruhi orang lain melalui pesan. Dalam perkembangan khazanah ilmu komunikasi, komunikasi profetik merupakan konsep baru yang didasarkan pada pendekatan studi Islam. Istilah ini (komunikasi profetik) mengacu pada pola komunikasi kenabian Muhammad saw yang sarat dengan kandungan nilai dan etika. Titik awal konsep ini berasal dari tujuan diutusnya nabi sebagai penyempurna keprbadian manusia (akhlak), sebagaimana dalam hadits nabi yang artinya berbunyi "Tiadalah aku diutus, kecuali hanya untuk menyempurnakan akhlak" (H.R. Ahmad).

Konsep profetik dalam ilmu sosial pertama kali diperkenalkan oleh Kuntowijoyo melalui kajian sosiologi. Menurutnya transformasi profetik dapat dilakukan melalui tiga hal yaitu humanisasi, liberasi, dan transendensi (Kuntowijoyo, 2005; 85). Humanisasi merupakan upaya mengembalikan hakikat kemanusiaan kepada kodratnya. Sedangkan liberasi adalah usaha pembebasan manusia dari strukturasi sosial yang tidak adil dan tidak memihak rakyat lemah. Adapun transendensi adalah upaya mengembalikan fitrah manusia yang sesuai dengan agama.

Transendensi berasal dari bahasa latin, trancendera, yang berarti naik. Secara sederhana transendensi dapat diartikan perjalanan di atas atau di luar melewati batas sekat kemanusiaan. Aspek transendentasl dalam komunikasi profetik meyakini bahwa komunikasi sebagai salah satu aspek realitas merupakan alat untuk mengajak manusia pada kehidupan yang kekal setelah kematian (Syahputra, 2017; 135). Oleh sebab itu, teks agama (nash) dalam komunikasi profetik merupakan kerangka acuan dalam membaca konteks dalam komunikasi.

Aktualisasi semangat profetik dalam komunikasi secara spesifik dilakukan melalui penggalian nash (Al-Qur'an dan hadist) yang berkaitan dengan etika komunikasi. Prinsip-prinsip komunikasi dalam Al-Qur'an dapat ditinjau melalui konsep berikut ini, yaitu;

\section{Qaulan sadiidan}

Lafadz Sadida secara bahasa bermakna al-a'dlu dan ash-showabu min al qaul (adil dan benar dalam perkataan). Allah menyebutkan kata ini di dalam Al-Qur'an sebanyak dua kali, yaitu pada surat An-Nisa' ayat 9 dan surat AlAhzab ayat 70. Kedua ayat ini menegaskan bahwa komunikasi harus didasari atas perkataan benar tanpa memandang profil dan status komunikan. Dalam Tafsir Qurthubi disebutkan bahwa surah An-Nisa ayat 9 berbicara mengenai ahli waris yang mengurus anak yatim $(1964 ; 52)$. Sedangkan konteks pada surah Al-Ahzab ayat 70 adalah fitnah dan tuduhan pengikut Nabi Musa kepada Nabi Musa. 
Etika yang dibangun dalam konsep ini adalah kebenaran dan kejujuran pesan komunikasi. Pesan tidak bersifat ambigu, berbelit-belit ataupun berisi kebohongan yang bertujuan untuk adu domba. Oleh karenaya, kebenaran informasi merupakan aspek yang sangat penting dalam proses komunikasi. Validitas pesan komunikasi menentukan arah perubahan seseorang terhadap isi pesan. Jika pesan yang disampaikan benar, maka akan timbul kerukunan, perdamaian, dan kasih sayang sesama manusia di bumi ini. Sebaliknya, jika pesan yang disampaikan tidak benar, maka akan timbul kebencian, perpecahan, dan fitnah antar umat manusia.

Oleh sebab itu, Islam mengajarkan prinsip utama dalam melakukan cek dan ricek (tabayyun) terhadap suatu informasi kepada sumber berita. Prinsip ini sebagaimana firman Allah dalam Al-Qur'an surat Al-Hujurat ayat 6;

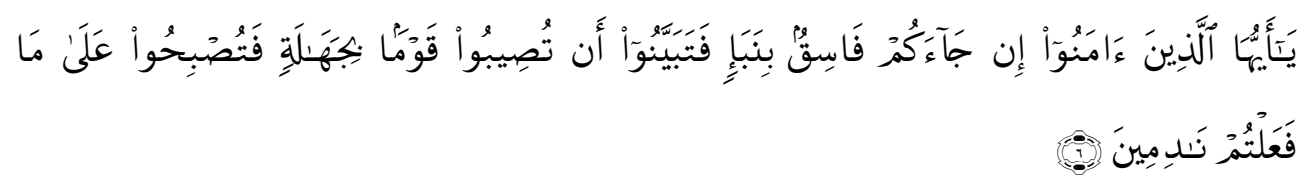

Artinya; "Hai orang-orang yang beriman, jika datang kepadamu orang Fasik membawa suatu berita, Maka periksalah dengan teliti agar kamu tidak menimpakan suatu musibah kepada suatu kaum tanpa mengetahui keadaannya yang menyebabkan kamu menyesal atas perbuatanmu itu."

\section{Qaulan Baliighan}

Secara bahasa kata baliighan berarti tersampaikan dan membekas. Al-Qur'an menyebut kata ini hanya sekali, yaitu dalam surat An-Nisa ayat 63. Ayat ini berisi himbauan kepada umat muslim agar tidak terpengaruh dengan tindakan orang munafik yang membelot dari Islam. Dalam tafsir Al-Maraghi (Al-Maraghi, 1946: 76) disebutkan bahwa kata qaulan baliighan bisa diwujudkan dalam bentuk nasihat atau teguran dengan cara yang baik. Cara ini digunakan agar lawan bicara tidak tersinggung dan merasa digurui. Oleh karenanya, qaulan baliighan harus disampaikan dengan tutur kata yang lembut, to the point dan tidak bertele-tele.

Mengacu pada keterangan di atas, konsep qaulan baalighan secara sepesifik diterapkan untuk orang-orang awam atau non muslim yang masih ragu dengan kebenaran Islam. Dalam konteks yang lebih luas konsep ini diterapkan untuk meyakinkan kebenaran suatu informasi atau pengetahuan baru kepada lawan bicara. Oleh karena tujuanya adalah efek pesan, seorang da'i atau komuikator dituntut untuk menguasai public speaking atau kemampuan jurnalistik yang baik. Konsep ini dapat diaplikasikan dengan cara pemilihan diksi kata yang tepat dalam penyampaian pesan, serta kepiawaian dalam beretorika. 


\section{Qaulan Maysuuran}

Kata maysuran merupakan bentuk maf'ul bih dari kata yasara-yaysir-yusran yang berarti mudah. Secara istilah qaulan maysuran adalah komunikasi yang dilakukan dengan menggunakan tata bahasa yang mudah dipahami, dicerna dan dimengerti oleh orang lain. Dalam penerapanya, qaulan maysuran berarti komunikasi tanpa tendensi dengan menggunakan argumentasi rasional dan bahasa yang mudah diterima. Konsep qaulan maysuran disebutkan sekali dalam Al-Qur'an Surat Al-Isra' ayat 28. Ayat ini berceritai mengenai janji pemberian rizqi kepada kerabat atau orang yang membutuhkan.

Dalam Tafsir Al-Margahi, konsep ini diartikan dengan ucapan yang baik dan tidak mengecewakan. Sedangkan Ibnu Katsir dalam Tafisrnya menyebutkan arti qaulan maysuuran dengan perkataan yang pantas dan ucapan janji yang menyenangkan. Berdasarkan kedua pendapat tersebut, etika yang terdapat dalam ayat ini mengajarkan untuk berbicara dengan baik kepada siapa saja, terlebih kepada orang lemah dengan perkataan yang baik, pantas, tidak menyinggung, dan menyenangkan.

\section{Qaulan layyinan}

Layyinan secara bahasa merupakan isim mashdar darif'il layyana-yulayyinulayyinan yang berarti melunakkan. Sedangkan dalam praktik komunikasi, qaulan layyinan adalah perkataan yang lembut, yang tidak mencerca, menyakiti, atau tidak kasar (memaksa). Konsep ini terdapat dalam surat Thaha ayat 44 yang bercerita mengenai dakwah dengan metode dialog antara Nabi Musa dengan Raja Fir'aun. Konsep ini digunakan oleh Nabi Musa agar dakwahnya tersampaikan dengan cara yang sopan dan etis. Meskipun dalam kenyataanya Fir'aun justru malah marah dan tidak terima sehingga mengusir Nabi Musa.

Berdasarkan konteks ayat di atas, konsep qaulan layyinan diterapkan kepada para penguasa atau orang yang memiliki pangkat. Dalam metode dakwah, konsep qaulan layyinan dapat juga diterapkan dengan menggunakan metode mau'idzoh hasanah (nasihat yang baik) atau dengan wa jadilhum (debat/dialog) sebagaimana yang dilakukan oleh Nabi Musa. Imam Al-Maraghi menyebutkan bahwa tujuan dari qaulan layyinan adalah menyentuh hati komunikan dengan perkataan yang lembut dan tidak menyinggung terhadap status sosial ataupun pangkat dan jabatan yang dimiliki oleh komunikan.

\section{Qaulan Kariiman (QS. Al-Isra'; 23)}

Secara bahasa lafadz kariiman merupakan isim sifat yang berarti mulia. Secara praksis, qaulan kariiman merupakan konsep komunikasi yang disampaikan 
dengan menggunakan ungkapan dan cara yang baik, sopan, dan santun. Qaulan kariiman menolak unsur kekerasan verbal seperti berbahasa kasar, membentakbentak atau mencaci maki lawan bicara. Di dalam Al-Qur'an, konsep qaulan kariiman disebutkan sekali dalam surat Al-Isra' ayat 23. Peta pemikiran yang muncul dalam ayat ini adalah perintah mematuhi orang tua dan memperlakukanya dengan cara yang baik. Yaitu, tidak menyakitinya dengan perkataan yang kasar meskipun hanya dengan ucapan remeh "ah".

Berdasarkan ayat tersebut, konsep qaulan kariiman dapat diterapkan kepada komunikan yang memiliki usia lebih tua dari komunikator. Dalam Tafsir karya Ibn Katsir disebutkan bahwa yang dimaksud dengan qaulan kariiman adalah perkataan yang lembut, baik, mulia, dan merendah. Senada dengan Al-Maraghi, Al-Qurthubi menjelaskan bahwa yang dimaksud dengan qaulan kariiman adalah perkataan yang lembut dan halus disertai dengan ucapan pujian.

\section{Qaulan Ma'ruufan}

Kata ma'rufan secara bahasa merupakan isim maful dari kata 'arafaya'rifu-'urfan-ma'rufan yang berarti megerjakan kebaikan. Secarah praktis, qaulan ma'rufan adalah komunikasi yang dilandasi dengan ucapan yang baik, tidak memprovokasi, dan tidak memanas-manasi. Konsep ini menekankan pada kode etik bahasa yang berkaitan dengan tutur kata yang lembut, sopan, dan tidak menyindir. Dalam Al-Qur'an Allah menyebutkan konsep ini sebanyak empat kali, yaitu pada Surah An-Nisa; 5 dan 8, Surah Al-Ahzab; 35, dan Surah Al-Baqarah; 235.

Konteks qaulan ma'rufan dalam Al-Qur'an dapat ditinjau melalui lima hal. Pertama, berkenaan dengan pemeliharaan harta anak yatim. Kedua, berkaitan dengan perkataan terhadap anak yatim dan orang miskin. Ketiga, berkenaan dengan harta yang diinfakkan atau disedekahkan kepada orang lain. Keempat mengenai ketentuan Allah terhadap istri Nabi. Terakhir, berbicara mengenai pinangan seorang wanita. Kelima kondisi tersebut menunjukkan bahwa qaulan ma'rufan memiliki porsi terbesar di antara konsep komunikasi yang lain. Oleh karenanya qaulan ma'rufan merupakan konsep dasar dari komunikasi profetik. Artinya bahwa komunikasi haruslah dilandasi dengan perkataan yang baik tanpa melihat kaya miskin, tua muda, terhormat atau tidaknya status seorang komunikan.

\section{F. Penutup}

Berdasarkan uraian di atas dapat disimpulkan bahwa internet sebagai era media baru merupakan sarana yang sangat tepat dalam menyebarkan dakwah. 
Sifatnya yang massif, memiliki jangkauan yang luas memudahkan transmisi dakwah cepat dan mudah tersampaikan. Namun demikian dakwah yang di era media baru masih rentan mengandung ujaran kebencian (hatespeech) dan kebohongan (hoax). Kenyataan ini justru sangat jauh dari cara dan metode yang diajarkan nabi secara persuasif dan moderat. Oleh karena itu, para juru dakwah seharusnya mengintegrasikan konsep profetik dalam berdakwah. Tujuanya adalah terciptanya Islam yang ramah dan damai sebagai wujud dari agama rahmatan lil 'alamin. Konsep komunikasi profetik yang variatif sangat relevan dengan karakeristik media baru yang kompleks dan luas.

\section{DAFTAR PUSTAKA}

Al-Maraghi, Ahmad ibn Musthafa. 1946. Tafsir Al-Maraghi. Kairo; Dar Kitab AlMishriyyah.

Al-Qurthubi, Abu 'Abdillah. 1964. Tafsir Al-Qurthubi. Kairo; Dar Kitab Al-Mishriyyah.

Barker, Thomas. 2006. Domestication of Media and Thecnology. New York; Open University Perss.

Basit, Abdul. 2006. Wacana Dakwah Kontemporer. Yogyakarta; Pustaka Pelajar.

Enjang dan Aliyudin. 2009. Dasar-dasar Ilmu Dakwah. Bandung; Wdya Padjajaran.

Fakhrurroji. 2017. Dakwah di Era Media Baru; Teori dan Aktivisme Dakwah di Internet. Bandung; Simbioasa Rekatama Media.

Kasman, Suf. 2004. Jurnalisme Universal; Menelusuri Prinsip-Prinsip Da'wah bi Al Qalam dalam Al-Qur'an. Jakarta; Teraju.

Kurniawan, Asep dkk. 2009. Dimensi Ilmu Dakwah; Tinjauan Dakwah dari Aspek Ontologi, Epistemologi, Aksiologi hingga Paradigma Pengembangan Profesialisme. Bandung; Widya Padjajaran.

Mustafa Ya'qub, Ali. 2014. Sejarah Metode Dakwah Nabi. Jakarta; Pustaka Firdaus.

Nasrullah, Ruli. 2014. Teori dan Riset Media Siber (Cybermedia). Jakarta; Prenada Media Group.

Saiful Muhtadi, Asep. 2012. Komunikasi Dakwah; Teori, Pendekatan, dan Aplikasi. Bandung; Simbiosa Rekatama Media.

Sambas, Syukriadi. 1995. Konstruksi Keilmuan Dakwah Islam PrespektifFilsafat Ilmu; Upaya Memahami dan Sosialisasi Pemberlakuan Kurikulum Nasional Fakultas Dakwah Tahun 1994. Bandung; Fakultas Dakwah IAIN Sunan Gunung Djati Bandung.

Syahputra, Iswandi. 2017. Paradigma Komunikasi Profetik; Gagasan dan Pendekatan. Bandung; Simbioasa Rekatama Media. 